\title{
IMPLEMENTASI PENDIDIKAN KARAKTER BANGSA DALAM PEMBELAJARAN SMA
}

\author{
Heri Supranoto \\ Pendidikan Ekonomi FKIP Universitas Muhammadiyah Metro \\ Heri_supranoto@yahoo.com
}

\begin{abstract}
Abstrak
Mengacu kepada berbagai peraturan perundang-undangan yang berlaku sebagaimana yang dinyatakan dalam naskah konsep dan strategi implementasi pendidikan budaya dan karakter bangsa di SMA, pendidikan budaya dan karakter bangsa dilakukan melalui integrasi pada mata pelajaran, pengembangan diri, dan budaya sekolah. Pendidikan budaya dan karakter bangsa pada intinya bertujuan mengembangkan karakter setiap individu agar mampu mewujudkan nilai-nilai luhur Pancasila; mengembangkan potensi dasar agar berhati baik, berpikiran baik, dan berperilaku baik; memperkuat dan membangun perilaku bangsa yang multikultur; dan meningkatkan peradaban bangsa yang kompetitif dalam pergaulan dunia. Proses ini melibatkan kerjasama seluruh warga sekolah. Sehubungan dengan itu, pendidikan budaya dan karakter bangsa di SMA dilakukan dengan pendekatan sistematik dan integratif dengan optimalisasi seluruh sumber daya pendukung yang ada di sekolah, keluarga, dan di masyarakat.

Pendidikan karakter dapat didefinisikan sebagai segala usaha yang dapat dilakukan untuk mempengaruhi karakter siswa. Pendidikan karakter mengandung tiga unsur pokok, yaitu mengetahui kebaikan (knowing the good), mencintai kebaikan (loving the good), dan melakukan kebaikan (doing the good). Pendidikan karakter tidak sekedar mengajarkan mana yang benar dan mana yang salah kepada peserta didik, tetapi lebih dari itu pendidikan karakter menanamkan kebiasaan (habituation) tentang yang baik sehingga peserta didik paham, mampu merasakan, dan mau melakukan yang baik. Jadi, pendidikan karakter membawa misi yang sama dengan pendidikan akhlak atau pendidikan moral.

Kemendiknas, telah diidentifikasi 18 nilai karakter yang perlu ditanamkan kepada peserta didik yang bersumber dari Agama, Pancasila, Budaya, dan Tujuan Pendidikan Nasional. Kedelapan belas nilai tersebut adalah:

1) religius, 2) jujur, 3) toleransi, 4) disiplin, 5) kerja keras, 6) kreatif, 7) mandiri, 8) demokratis, 9) rasa ingin tahu, 10) semangat kebangsaan, 11) cinta tanah air, 12) menghargai prestasi, 13) bersahabat/komunikatif, 14) cinta damai, 15) gemar membaca, 16) peduli lingkungan, 17) peduli sosial, 18) tanggung jawab
\end{abstract}

Kata Kunci: Pendidikan Karakter Bangsa

\section{PENDAHULUAN}

Mengacu kepada berbagai peraturan perundang-undangan yang berlaku sebagaimana yang dinyatakan dalam naskah Konsep dan Strategi Implementasi
Pendidikan Budaya dan Karakter Bangsa di SMA, pendidikan budaya dan karakter bangsa dilakukan melalui integrasi pada mata pelajaran, pengembangan diri dan budaya sekolah. Pendidikan budaya dan karakter bangsa pada intinya bertujuan 
mengembangkan karakter setiap individu agar mampu mewujudkan nilai-nilai luhur Pancasila; mengembangkan potensi dasar agar berhati baik, berpikiran baik, dan berperilaku baik; memperkuat dan membangun perilaku bangsa yang multikultur; dan meningkatkan peradaban bangsa yang kompetitif dalam pergaulan dunia. Proses ini melibatkan kerjasama seluruh warga sekolah. Sehubungan dengan itu, pendidikan budaya dan karakter bangsa di SMA dilakukan dengan pendekatan sistematik dan integratif dengan optimalisasi seluruh sumber daya pendukung yang ada di sekolah, keluarga, dan di masayarakat.

Penerapan pendidikan budaya dan karakter bangsa di SMA harus dilaksanakan secara komprehensif mulai dari perencanaan, pelaksanaan, penilaian dan program tindaklanjut.

Pada dasarnya banyak SMA yang telah melaksanakan pendidikan budaya dan karakter bangsa dalam setiap mata pelajaran yang ada, serta melalui berbagai pendekatan. Namun pelaksanaannya belum terdokumentasi secara baik sehingga belum dapat diketahui tingkat keberhasilannya.

Berdasarkan pemaparan di atas, penulis berusaha menulis dan menjelaskan tentang mengintegrasikan nilai-nilai budaya dan karakter bangsa dalam pembelajaran ekonomi.
Berdasarkan latar belakang yang telah dikemukakan di atas, maka rumusan masalahnya adalah sebagai berikut.
a) Bagaimanakah konsep pendidikan karekter bangsa
b) Bagaimanakah Implementasi pendidikan karekter bangsa dalam pembelajaran?
c) Bagaimanakah kegiatan pendidikan karekter bangsa dalam pembelajaran?

\section{PEMBAHASAN}

\section{Konsep Pendidikan Karekter Bangsa}

Pendidikan menurut Ki Hajar Dewantara adalah daya upaya untuk memajukan budi pekerti, pikiran, serta jasmani agar dapat memajukan kehidupan yang selaras dengan alam dan masyarakatnya (Hartono: 2012).

Menurut Donie (2007: 25), pendidikan karakter terdiri dari beberapa unsur, diantaranya penanaman karakter dengan pemahaman pada peserta didik tentang struktur nilai dan keteladanan yang diberikan pengajar dan lingkungan Pendidikan Karakter Menurut Kertajaya adalah ciri khas yang dimiliki oleh suatu benda atau individu. Cirikhas tersebut adalah asli dan mengakar pada kepribadian benda atau individu tersebut, serta merupakan "mesin" yang mendorong bagaimana seorang bertindak, bersikap, 
berucap, dan merespon sesuatu Kertajaya, dalam (Nency, 2013: 27).

Kemendiknas (2011), telah diidentifikasi 18 nilai karakter yang perlu ditanamkan kepada peserta didik yang bersumber dari Agama, Pancasila, Budaya, dan Tujuan Pendidikan Nasional. Kedelapan belas nilai tersebut adalah:

1) religius, 2) jujur, 3) toleransi, 4) disiplin, 5) kerja keras, 6) kreatif, 7) mandiri, 8) demokratis, 9) rasa ingin tahu, 10) semangat kebangsaan, 11) cinta tanah air, 12) menghargai prestasi, 13) bersahabat/komunikatif, 14) cinta damai, 15) gemar membaca, 16) peduli lingkungan, 17) peduli sosial, 18) tanggung jawab.

Meskipun telah dirumuskan ada 18 nilai pembentuk karakter bangsa, disetiap satuan pendidikan dapat menentukan prioritas pengembangannya. Pemilihan nilai-nilai tersebut berpijak dari kepentingan dan kondisi satuan pendidikan masing-masing. Hal ini dilakukan melalui analisis konteks, sehingga dalam implementasinya dimungkinkan terdapat perbedaan jenis nilai karakter yang dikembangkan. Implementasi nilai-nilai karakter yang akan dikembangkan dapat dimulai dari nilai-nilai yang esensial, sederhana, dan mudah dilaksanakan

Kedelapan belas nilai karakter tersebut dideskripsikan oleh Sari (2013) dan Widiyanto (2013) seperti berikut. a) Religius: sikap dan perilaku yang patuh dalam melaksanakan ajaran agama yang dianutnya, toleran terhadap pelaksanaan ibadah agama lain.

b) Jujur: upaya menjadikan dirinya sebagai orang yang selalu dapat dipercaya dalam perkataan, tindakan, dan pekerjaan.

c) Toleransi: menghargai perbedaan agama, suku, etnis, pendapat, sikap, dan tindakan orang lain yang berbeda dari dirinya.

d) Disiplin: perilaku tertib dan patuh pada berbagai ketentuan dan peraturan.

e) Kerja Keras: upaya sungguh-sungguh dalam mengatasi berbagai hambatan belajar dan tugas, serta menyelesaikan tugas dengan sebaik-baiknya.

f) Kreatif: berpikir dan melakukan sesuatu untuk menghasilkan cara atau hasil baru dari sesuatu yang telah dimiliki.

g) Mandiri: sikap dan perilaku yang tidak mudah tergantung pada orang lain.

h) Demokratis: cara berfikir, bersikap, dan bertindak yang menilai sama hak dan kewajiban dirinya dan orang lain.

i) Rasa Ingin Tahu: sikap dan tindakan yang selalu berupaya untuk mengetahui lebih mendalam dan meluas dari suatu yang dipelajarinya, dilihat, dan didengar. 
j) Semangat Kebangsaan: menempatkan kepentingan bangsa dan negara di atas kepentingan diri dan kelompoknya.

k) Cinta Tanah Air: cara berfikir, bersikap, dan berbuat yang menunjukkan kesetiaan, kepedulian, dan penghargaan yang tinggi terhadap bangsa.

1) Menghargai Prestasi: mendorong dirinya menghasilkan sesuatu yang berguna bagi masyarakat, dan mengakui, menghormati keberhasilan orang lain.

m) Bersahabat/Komunikatif: tindakan yang memperlihatkan rasa senang berbicara, bergaul, dan bekerja sama dengan orang lain.

n) Cinta Damai: sikap perkataan, dan tindakan yang menyebabkan orang lain merasa senang dan aman atas kehadiran dirinya.

o) Gemar Membaca: kebiasaan menyediakan waktu untuk membaca berbagai bacaan yang memberikan kebajikan bagi dirinya.

p) Peduli Lingkungan: sikap dan tindakan yang selalu berupaya mencegah kerusakan pada lingkungan alam di sekitarnya, dan mengembangkan upaya-upaya untuk memperbaiki kerusakan alam yang sudah terjadi.

q) Peduli Sosial: sikap dan tindakan yang selalu ingin memberi bantuan pada orang lain dan masyarakat yang membutuhkan.

r) Tanggungjawab: sikap dan perilaku seseorang untuk melaksanakan tugas dan kewajibannya, yang seharusnya dia lakukan, terhadap diri sendiri, masyarakat, lingkungan (alam, sosial dan budaya), negara dan Tuhan Yang Maha Esa

Pendidikan karakter adalah pendidikan sepanjang hayat, sebagai proses kearah manusia yang sempurna. Oleh karena itu, pendidikan karakter memerlukan keteladanan dan sentuhan mulai sejak dini sampai dewasa. Periode yang paling sensitif dan menentukan adalah pendidikan dalam keluarga yang menjadi tanggungjawab orang tua (Kartadinata, 2009). Di sisi lain disebutkan bahwa pendidikan karakter harus menjadi bagian terpadu dari pendidikan alih generasi. Pendidikan adalah persoalan kemanusiaan yang harus didekati dari perkembangan manusia itu sendiri (Kartadinata, 2009).

Menurut Marzuki (2013), pendidikan karakter mengandung tiga unsur pokok, yaitu mengetahui kebaikan (knowing the good), mencintai kebaikan (loving the good), dan melakukan kebaikan (doing the good). Pendidikan Karakter tidak sekedar mengajarkan mana yang benar dan mana yang salah kepada peserta didik, tetapi lebih dari itu pendidikan karakter menanamkan 
kebiasaan (habituation) tentang yang baik sehingga peserta didik paham, mampu merasakan, dan mau melakukan yang baik. Jadi, pendidikan karakter membawa misi yang sama dengan Pendidikan Akhlak atau Pendidikan Moral.

\section{Implementasi Pendidikan Karekter Bangsa dalam Pembelajaran Ekonomi}

Selain bertujuan untuk menghadapi era globalisasi, pendidikan karakter juga bertujuan melahirkan SDM yang mempunyai karakter akuntan yang mampu menyelesaikan segala persoalan yang berhubungan dengan pembelajaran akuntansi, dan mampu merealisasikan pembelajaran akuntansi yang telah dipelajari ke dalam dunia kerja nantinya.

Untuk mewujudkan pendidikan karakter bangsa, secara umum dapat dilakukan melalui pendidikan formal, non formal, dan informal yang saling melengkapi dan diatur dalam peraturan perundang-undangan. Sesuai Kebijakan
Nasional Pembangunan Karakter Bangsa, pendidikan karakter dimaknai sebagai usaha sadar dan terencana untuk mewujudkan suasana serta proses pemberdayaan potensi dan pembudayaan peserta didik guna membangun karakter pribadi dan/atau kelompok yang unik, baik sebagai warga negara. Hal itu diharapkan mampu memberikan kontribusi optimal dalam mewujudkan masyarakat yang berKetuhanan Yang Maha Esa, berkemanusiaan yang adil dan beradab, berjiwa persatuan Indonesia, berjiwa kerakyatan yang dipimpin oleh hikmat kebijaksanaan dalam permusyawaratan/ perwakilan, berkeadilan sosial bagi seluruh rakyat Indonesia (Pemerintah Republik Indonesia, 2010).

\section{Isi Penidikan Karakter Dalam Pembelajaran SMA \\ Menurut Ditjen Pendidikan Menengah} (2011: 34), nilai-nilai karater dapat dideskipsikan sebagai berikut.

Tabel 1. Deskripsi nilai-nilai budaya dan karakter bangsa.

\begin{tabular}{|c|l|l|}
\hline NO & NILAI & DESKRIPSI \\
\hline 1 & Religius & $\begin{array}{l}\text { Sikap dan perilaku yang patuh dalam melaksanakan ajaran agama } \\
\text { yang dianutnya. }\end{array}$ \\
\hline 2 & Jujur & $\begin{array}{l}\text { Perilaku yang didasarkan pada upaya menjadikan dirinya sebagai } \\
\text { orang yang selalu dapat dipercaya dalam perkataan, tindakan, dan } \\
\text { pekerjaan. }\end{array}$ \\
\hline 3 & Toleransi & $\begin{array}{l}\text { Sikap dan tindakan yang menghargai perbedaan agama, suku, etnis, } \\
\text { pendapat, sikap, dan tindakan orang lain yang berbeda dari dirinya. }\end{array}$ \\
\hline 4 & Disiplin & $\begin{array}{l}\text { Tindakan yang menunjukkan perilaku tertib dan patuh pada berbagai } \\
\text { ketentuan dan peraturan. }\end{array}$ \\
\hline
\end{tabular}




\begin{tabular}{|c|c|c|}
\hline 5 & Kerja keras & $\begin{array}{l}\text { Perilaku yang menunjukkan upaya sungguh-sungguh dalam } \\
\text { mengatasi berbagai hambatan belajar dan tugas, serta menyelesaikan } \\
\text { tugas dengan sebaik-baiknya. }\end{array}$ \\
\hline 6 & Kreatif & $\begin{array}{l}\text { Berpikir dan melakukan sesuatu untuk menghasilkan cara atau hasil } \\
\text { baru dari sesuatu yang telah dimiliki. }\end{array}$ \\
\hline 7 & Mandiri & $\begin{array}{l}\text { Sikap dan perilaku yang tidak mudah tergantung pada orang lain } \\
\text { dalam menyelesaikan tugas-tugas. }\end{array}$ \\
\hline 8 & Demokratis & $\begin{array}{l}\text { Cara berfikir, bersikap, dan bertindak yang menilai sama hak dan } \\
\text { kewajiban dirinya dan orang lain. }\end{array}$ \\
\hline 9 & $\begin{array}{l}\text { Rasa ingin } \\
\text { tahu }\end{array}$ & $\begin{array}{l}\text { Sikap dan tindakan yang selalu berupaya untuk mengetahui lebih } \\
\text { mendalam dan meluas dari sesuatu yang dipelajarinya, dilihat, dan } \\
\text { didengar. }\end{array}$ \\
\hline 10 & $\begin{array}{l}\text { Semangat } \\
\text { Kebangsaan }\end{array}$ & $\begin{array}{l}\text { Cara berpikir, bertindak, dan berwawasan yang menempatkan } \\
\text { kepentingan bangsa dan negara di atas kepentingan diri dan } \\
\text { kelompoknya. }\end{array}$ \\
\hline 11 & $\begin{array}{l}\text { Cinta Tanah } \\
\text { Air }\end{array}$ & $\begin{array}{l}\text { Cara berfikir, bersikap, dan berbuat yang menunjukkan kesetiaan, } \\
\text { kepedulian, dan penghargaan yang tinggi terhadap bahasa, } \\
\text { lingkungan fisik, sosial, budaya, ekonomi, dan politik bangsa. }\end{array}$ \\
\hline 12 & $\begin{array}{l}\text { Menghargai } \\
\text { Prestasi }\end{array}$ & $\begin{array}{l}\text { Sikap dan tindakan yang mendorong dirinya untuk menghasilkan } \\
\text { sesuatu yang berguna bagi masyarakat, dan mengakui, serta } \\
\text { menghormati keberhasilan orang lain. }\end{array}$ \\
\hline 13 & $\begin{array}{l}\text { Bersahabat/ } \\
\text { Komunikatif }\end{array}$ & $\begin{array}{l}\text { Tindakan yang memperlihatkan rasa senang berbicara, bergaul, dan } \\
\text { bekerja sama dengan orang lain. }\end{array}$ \\
\hline 14 & Cinta Damai & $\begin{array}{l}\text { Sikap, perkataan, dan tindakan yang menyebabkan orang lain } \\
\text { merasa senang dan aman atas kehadiran dirinya. }\end{array}$ \\
\hline 15 & $\begin{array}{l}\text { Gemar } \\
\text { Membaca }\end{array}$ & $\begin{array}{l}\text { Kebiasaan menyediakan waktu untuk membaca berbagai bacaan } \\
\text { yang memberikan kebajikan bagi dirinya. }\end{array}$ \\
\hline 16 & $\begin{array}{l}\text { Peduli } \\
\text { Lingkungan }\end{array}$ & $\begin{array}{l}\text { Sikap dan tindakan yang selalu berupaya mencegah kerusakan pada } \\
\text { lingkungan alam di sekitarnya, dan mengembangkan upaya-upaya } \\
\text { untuk memperbaiki kerusakan alam yang sudah terjadi. }\end{array}$ \\
\hline 17 & Peduli Sosial & $\begin{array}{l}\text { Sikap dan tindakan yang selalu ingin memberi bantuan pada orang } \\
\text { lain dan masyarakat yang membutuhkan. }\end{array}$ \\
\hline 18 & $\begin{array}{l}\text { Tanggung- } \\
\text { jawab }\end{array}$ & $\begin{array}{l}\text { Sikap dan perilaku seseorang untuk melaksanakan tugas dan } \\
\text { kewajibannya, yang seharusnya dia lakukan, terhadap diri sendiri, } \\
\text { masyarakat, lingkungan (alam, sosial dan budaya), negara dan } \\
\text { Tuhan Yang Maha Esa. }\end{array}$ \\
\hline
\end{tabular}


Sekolah dan guru dapat menambah atau pun mengurangi nilai-nilai tersebut sesuai dengan kebutuhan masyarakat yang dilayani sekolah dan hakekat materi SK-KD serta materi bahasan suatu mata pelajaran.

Lebih lanjut, Ditjen Pendidikan Menengah, menjelaskan tentang muatan nilai karakter bangsa dalam SKL adalah sebagai berikut.

Tabel 2. Muatan Nilai-Nilai Budaya dan Karakter Bangsa Dalam SKL SMA

\begin{tabular}{|c|c|c|}
\hline No. & Rumusan SKL & Nilai/Karakter \\
\hline 1 & $\begin{array}{l}\text { Berperilaku sesuai dengan ajaran agama yang dianut } \\
\text { sesuai dengan perkembangan remaja }\end{array}$ & Religius \\
\hline 2 & 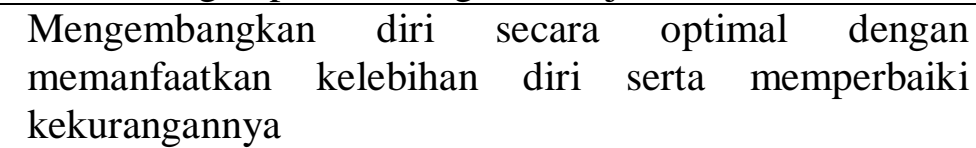 & Menghargai prestasi \\
\hline 3 & $\begin{array}{l}\text { Menunjukkan sikap percaya diri dan bertanggung jawab } \\
\text { atas perilaku, perbuatan, dan pekerjaannya }\end{array}$ & Tanggung jawab \\
\hline 4 & Berpartisipasi dalam penegakan aturan-aturan sosial & Disiplin \\
\hline 5 & $\begin{array}{l}\text { Menghargai keberagaman agama, bangsa, suku, ras, dan } \\
\text { golongan sosial ekonomi dalam lingkup global }\end{array}$ & Toleransi \\
\hline 6 & $\begin{array}{l}\text { Membangun dan menerapkan informasi dan } \\
\text { pengetahuan secara logis, kritis, kreatif, dan inovatif }\end{array}$ & Kreatif \\
\hline 7 & $\begin{array}{l}\text { Menunjukkan kemampuan berpikir logis, kritis, kreatif, } \\
\text { dan inovatif dalam pengambilan keputusan }\end{array}$ & Kreatif \\
\hline 8 & $\begin{array}{l}\text { Menunjukkan kemampuan mengembangkan budaya } \\
\text { belajar untuk pemberdayaan diri }\end{array}$ & Gemar membaca \\
\hline 9 & $\begin{array}{l}\text { Menunjukkan sikap kompetitif dan sportif untuk } \\
\text { mendapatkan hasil yang terbaik }\end{array}$ & Menghargai prestasi \\
\hline 10 & $\begin{array}{l}\text { Menunjukkan kemampuan } \\
\text { memecahkan masalah kompleks }\end{array}$ & Kreatif \\
\hline 11 & $\begin{array}{l}\text { Menunjukkan kemampuan menganalisis gejala alam } \\
\text { dan sosial }\end{array}$ & $\begin{array}{l}\text { Kreatif, } \\
\text { Peduli lingkungan/ } \\
\text { social }\end{array}$ \\
\hline 12 & $\begin{array}{l}\text { Memanfaatkan lingkungan secara produktif dan } \\
\text { bertanggung jawab }\end{array}$ & $\begin{array}{l}\text { Tanggung jawab, } \\
\text { Peduli lingkungan }\end{array}$ \\
\hline 13 & $\begin{array}{l}\text { Berpartisipasi dalam kehidupan bermasyarakat, } \\
\text { berbangsa, dan bernegara secara demokratis dalam } \\
\text { wadah Negara Kesatuan Republik Indonesia }\end{array}$ & $\begin{array}{l}\text { Semangat } \\
\text { kebangsaan } \\
\text { Cinta tanah air }\end{array}$ \\
\hline 14 & Mengekspresikan diri melalui kegiatan seni dan budaya & Menghargai prestasi \\
\hline 15 & Mengapresiasi karya seni dan budaya & Menghargai prestasi \\
\hline 16 & $\begin{array}{l}\text { Menghasilkan karya kreatif, baik individual maupun } \\
\text { kelompok }\end{array}$ & Kreatif \\
\hline 17 & $\begin{array}{l}\text { Menjaga kesehatan dan keamanan diri, kebugaran } \\
\text { jasmani, serta kebersihan lingkungan }\end{array}$ & $\begin{array}{l}\text { Disiplin, Mandiri, } \\
\text { Tanggung jawab }\end{array}$ \\
\hline 18 & $\begin{array}{l}\text { Berkomunikasi lisan dan tulisan secara efektif dan } \\
\text { santun }\end{array}$ & $\begin{array}{l}\text { Bersahabat/ } \\
\text { komunikatif }\end{array}$ \\
\hline 19 & Memahami hak dan kewajiban diri dan orang lain dalam & Tanggung jawab \\
\hline
\end{tabular}




\begin{tabular}{|c|c|c|}
\hline & pergaulan di masyarakat & \\
\hline 20 & $\begin{array}{l}\text { Menghargai adanya perbedaan pendapat dan berempati } \\
\text { terhadap orang lain }\end{array}$ & Toleransi \\
\hline 21 & $\begin{array}{l}\text { Menunjukkan keterampilan membaca dan menulis } \\
\text { naskah secara sistematis dan estetis }\end{array}$ & Gemar membaca \\
\hline 22 & $\begin{array}{l}\text { Menunjukkan keterampilan menyimak, membaca, } \\
\text { menulis, dan berbicara dalam bahasa Indonesia dan } \\
\text { Inggris }\end{array}$ & $\begin{array}{l}\text { Gemar membaca, } \\
\text { Bersahabat/ } \\
\text { komunikatif }\end{array}$ \\
\hline 23 & $\begin{array}{l}\text { Menguasai pengetahuan yang diperlukan } \text { untuk } \\
\text { mengikuti pendidikan tinggi }\end{array}$ & $\begin{array}{lr}\text { Kerja } & \text { keras, } \\
\text { Mandiri, } & \text { Tangung } \\
\text { jawab. } & \end{array}$ \\
\hline
\end{tabular}

(Grand design pendidikan karakter - Kemdiknas)

\section{Kegiatan Pendidikan Karekter Bangsa Dalam Pembelajaran SMA}

\section{KEGIATAN RUTIN}

\begin{tabular}{|l|l|l|l|l|}
\hline NO & KEGIATAN & $\begin{array}{l}\text { NILAI YANG } \\
\text { DILAKSANAKAN }\end{array}$ & $\begin{array}{l}\text { WAKTU } \\
\text { PELAKSANAAN }\end{array}$ & $\begin{array}{l}\text { PENANGGUNG } \\
\text { JAWAB }\end{array}$ \\
\hline 1 & Shalat Berjama'ah & Religius & Setiap Hari Jumat & Guru PAI \\
\hline & & & & \\
\hline
\end{tabular}

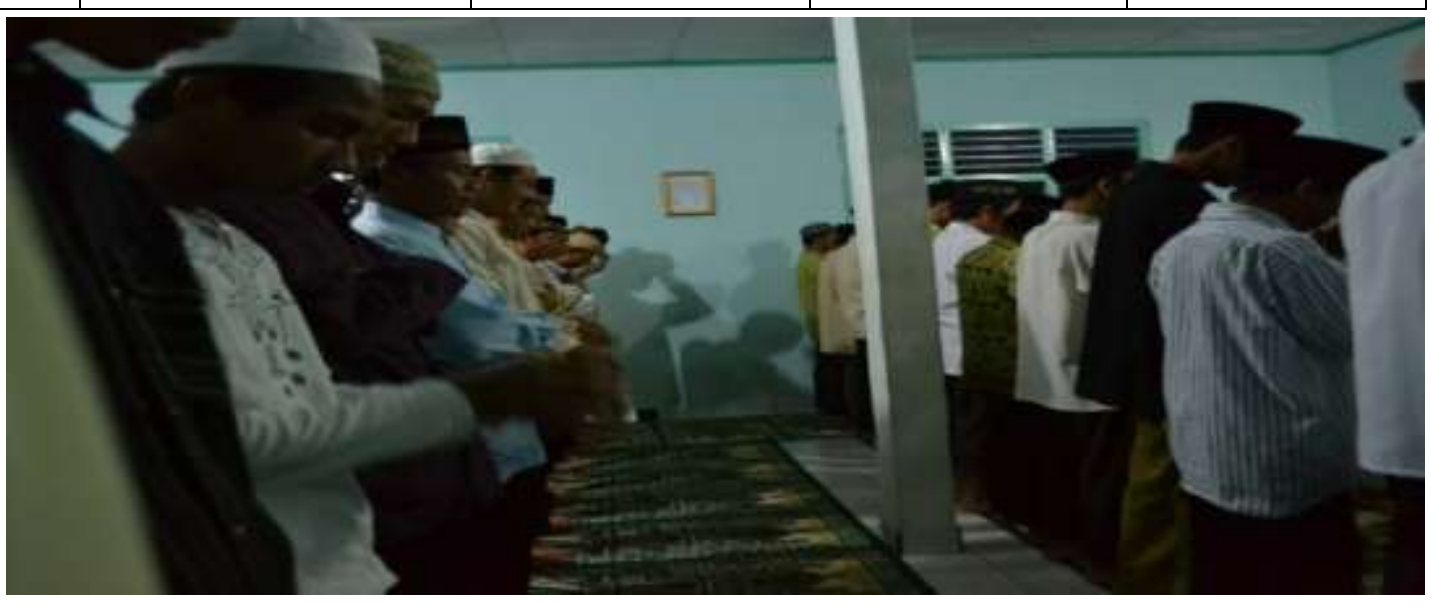

\begin{tabular}{|l|l|l|l|l|}
\hline NO & KEGIATAN & $\begin{array}{l}\text { NILAI YANG } \\
\text { DILAKSANAKAN }\end{array}$ & $\begin{array}{l}\text { WAKTU } \\
\text { PELAKSANAAN }\end{array}$ & $\begin{array}{l}\text { PENANGGUNG } \\
\text { JAWAB }\end{array}$ \\
\hline 2 & Piket kelas & Peduli Lingkungan & $\begin{array}{l}\text { Sebelum KBM } \\
\text { berlangsung }\end{array}$ & Wali Kelas \\
\hline
\end{tabular}




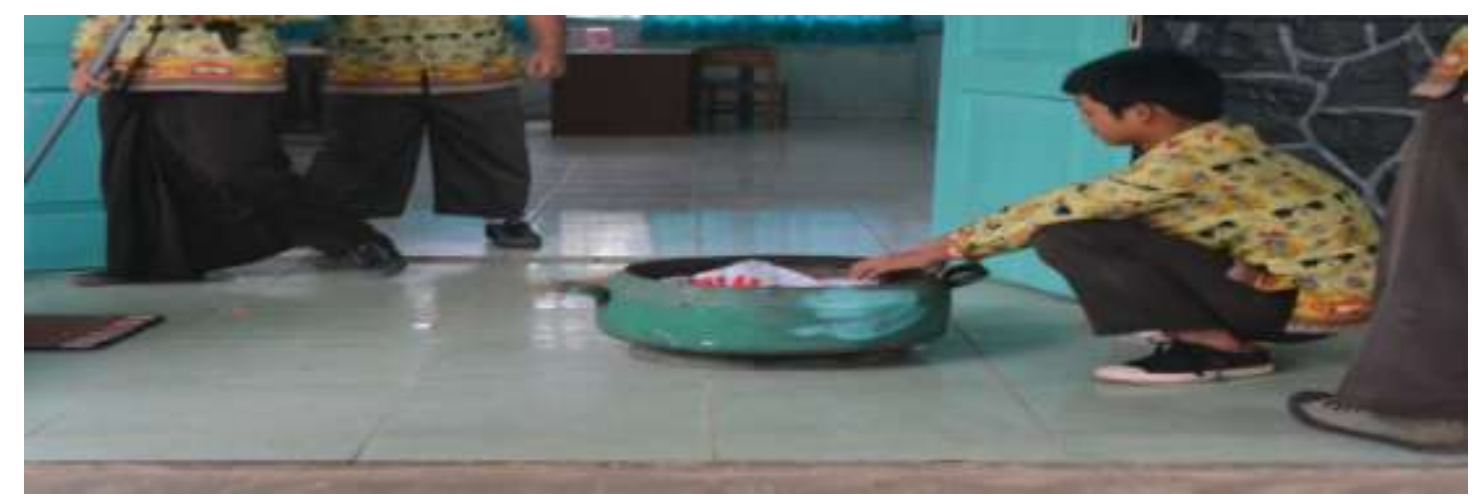

\begin{tabular}{|l|l|l|l|l|}
\hline NO & KEGIATAN & $\begin{array}{l}\text { NILAI YANG } \\
\text { DILAKSANAKAN }\end{array}$ & $\begin{array}{l}\text { WAKTU } \\
\text { PELAKSANAAN }\end{array}$ & $\begin{array}{l}\text { PENANGGUNG } \\
\text { JAWAB }\end{array}$ \\
\hline 3 & $\begin{array}{l}\text { Upacara } \\
\text { Bendera }\end{array}$ & Cinta tanah air & Setiap hari senin & $\begin{array}{l}\text { Waka. } \\
\text { Kesiswaan }\end{array}$ \\
\hline
\end{tabular}

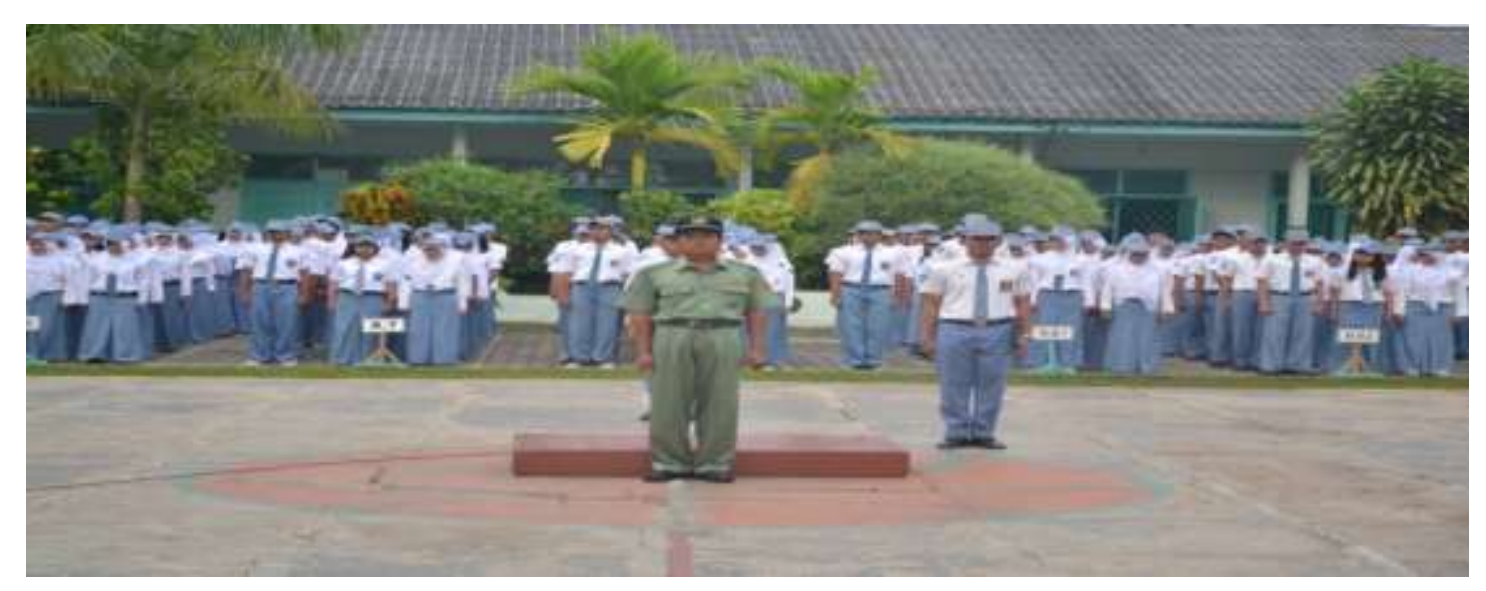

\begin{tabular}{|l|l|l|l|l|}
\hline NO & KEGIATAN & $\begin{array}{l}\text { NILAI YANG } \\
\text { DILAKSANAKAN }\end{array}$ & $\begin{array}{l}\text { WAKTU } \\
\text { PELAKSANAAN }\end{array}$ & $\begin{array}{l}\text { PENANGGUNG } \\
\text { JAWAB }\end{array}$ \\
\hline 4 & $\begin{array}{l}\text { Melaksanakan } \\
\text { tugas piket }\end{array}$ & Mandiri & $\begin{array}{l}\text { Sebelum KBM } \\
\text { berlangsung }\end{array}$ & Wali kelas \\
\hline
\end{tabular}

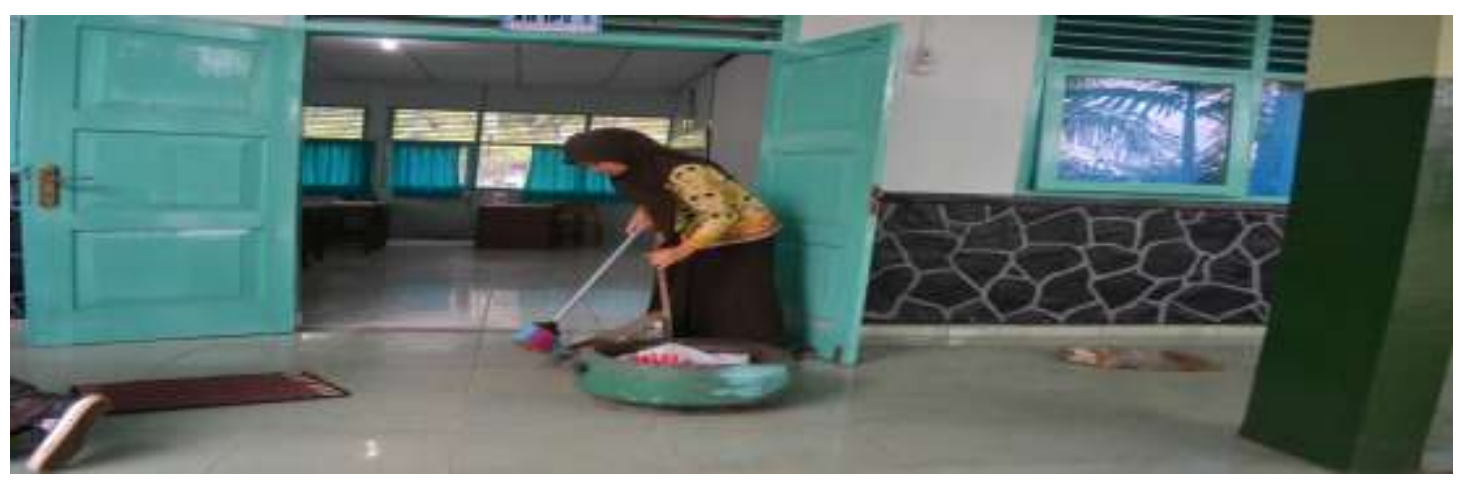


ISSJN: $2442-9449$ Vol.3.JNo.1 (2015) 36-49

\begin{tabular}{|l|l|l|l|l|}
\hline NO & KEGIATAN & $\begin{array}{l}\text { NILAI YANG } \\
\text { DILAKSANAKAN }\end{array}$ & $\begin{array}{l}\text { WAKTU } \\
\text { PELAKSANAAN }\end{array}$ & $\begin{array}{l}\text { PENANGGUNG } \\
\text { JAWAB }\end{array}$ \\
\hline 5 & $\begin{array}{l}\text { Mengembalikan } \\
\text { laptop }\end{array}$ & Tanggung Jawab & Setelah KBM & Ketua Kelas \\
\hline
\end{tabular}

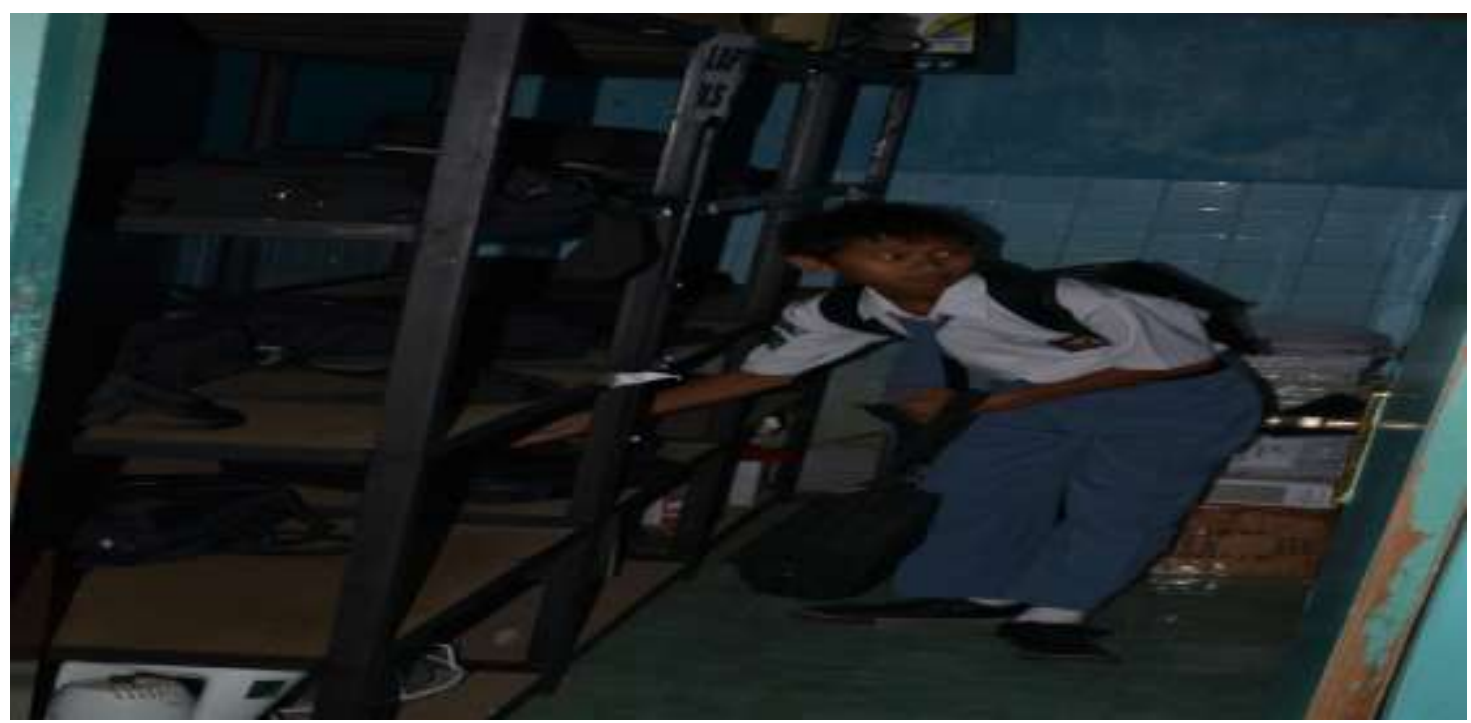

\begin{tabular}{|l|l|l|l|l|}
\hline NO & KEGIATAN & $\begin{array}{l}\text { NILAI YANG } \\
\text { DILAKSANAKAN }\end{array}$ & $\begin{array}{l}\text { WAKTU } \\
\text { PELAKSANAAN }\end{array}$ & $\begin{array}{l}\text { PENANGGUNG } \\
\text { JAWAB }\end{array}$ \\
\hline 6 & $\begin{array}{l}\text { Mengekspresikan } \\
\text { kreatifitas dalam } \\
\text { kegiatan Gebyar } \\
\text { Seni }\end{array}$ & Kreatif & Gebyar Seni XII & Wali Kelas \\
\hline
\end{tabular}

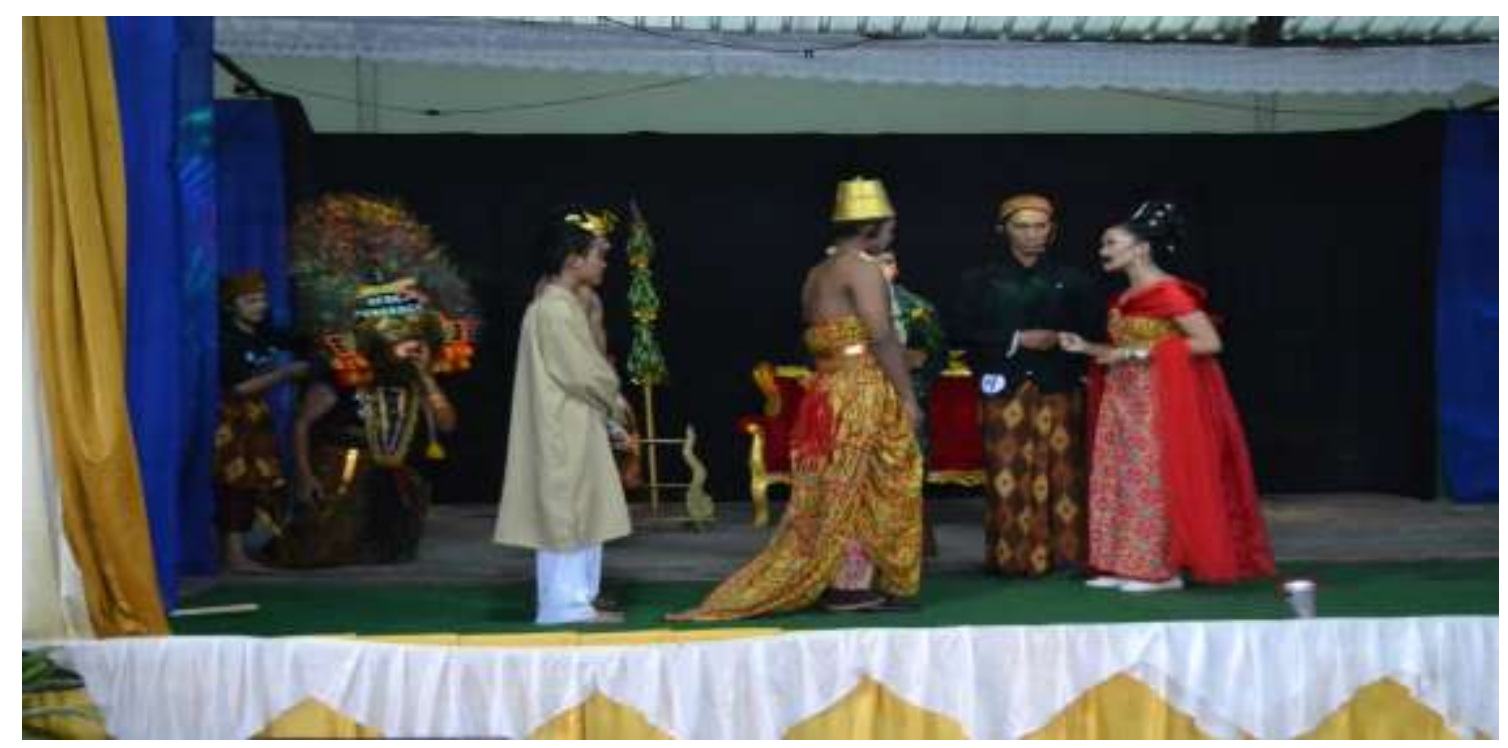


ISSN: 2442-9449 Vol.3.No.1 (2015) 36-49

\begin{tabular}{|l|l|l|l|l|}
\hline NO & KEGIATAN & $\begin{array}{l}\text { NILAI YANG } \\
\text { DILAKSANAKAN }\end{array}$ & $\begin{array}{l}\text { WAKTU } \\
\text { PELAKSANAAN }\end{array}$ & $\begin{array}{l}\text { PENANGGUNG } \\
\text { JAWAB }\end{array}$ \\
\hline 7 & $\begin{array}{l}\text { Memberi } \\
\text { penghargaan } \\
\text { terhada siswa } \\
\text { berprestasi }\end{array}$ & $\begin{array}{l}\text { Menghargai } \\
\text { Prestasi }\end{array}$ & Akhir Semester & \\
\hline
\end{tabular}

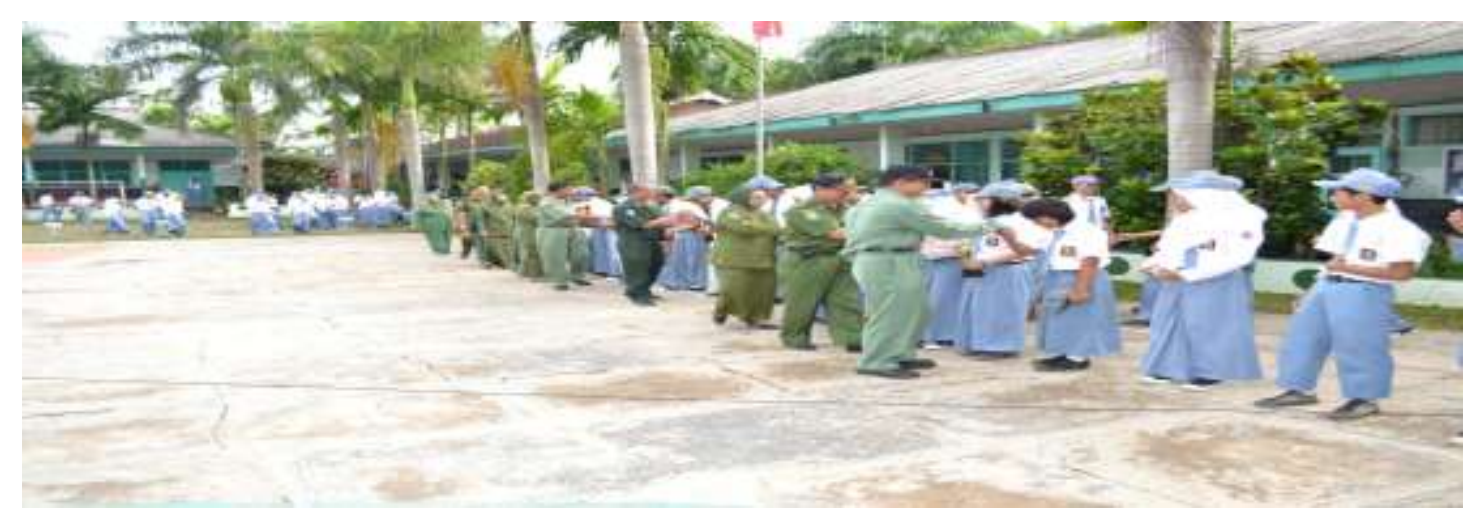

\begin{tabular}{|l|l|l|l|l|}
\hline NO & KEGIATAN & $\begin{array}{l}\text { NILAI YANG } \\
\text { DILAKSANAKAN }\end{array}$ & $\begin{array}{l}\text { WAKTU } \\
\text { PELAKSANAAN }\end{array}$ & $\begin{array}{l}\text { PENANGGUNG } \\
\text { JAWAB }\end{array}$ \\
\hline 8 & $\begin{array}{l}\text { Memberikan } \\
\text { penghargaan } \\
\text { bagi guru } \\
\text { yang } \\
\text { berprestasi }\end{array}$ & $\begin{array}{l}\text { Menghargai } \\
\text { Prestasi }\end{array}$ & Rapat dewan guru & \\
\hline
\end{tabular}

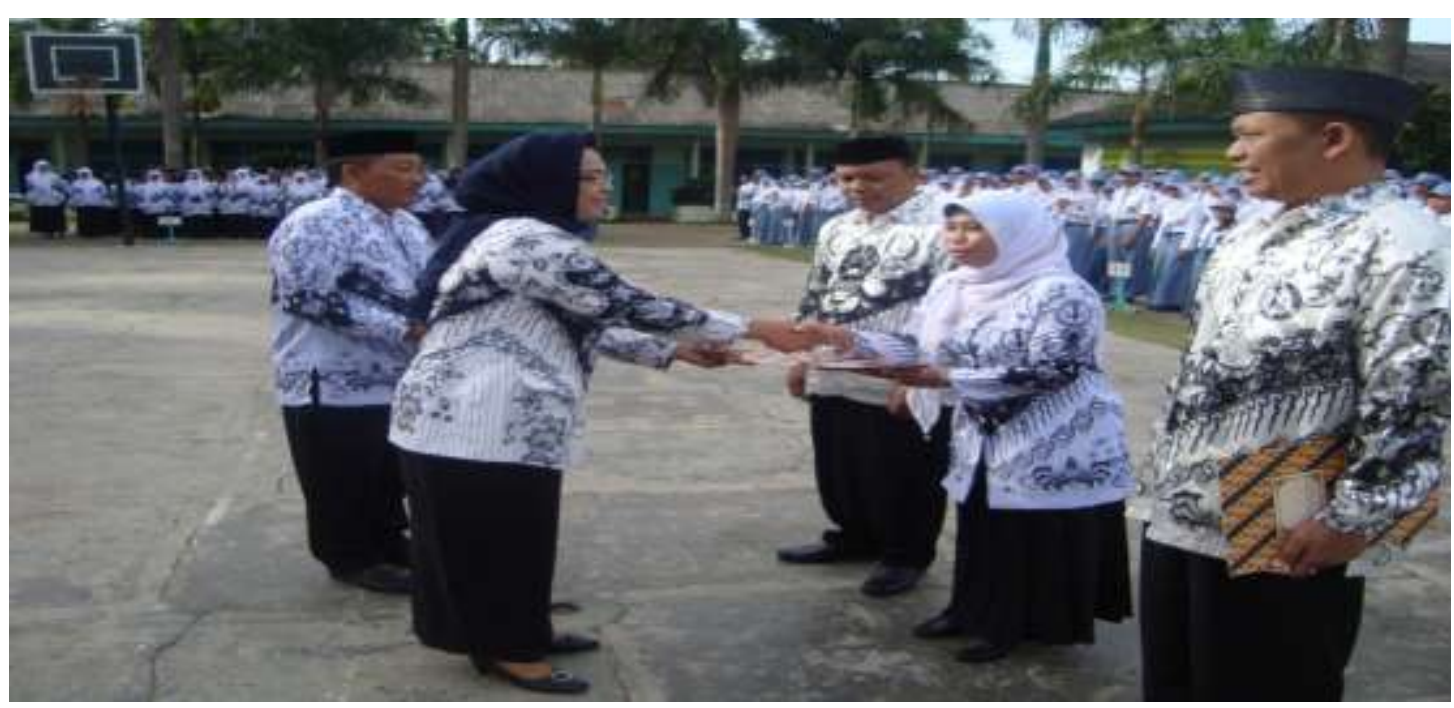


ISSN: 2442-9449 Vol.3.JNo.1 (2015) 36-49

KEGIATAN SPONTAN

\begin{tabular}{|l|l|l|l|l|}
\hline NO & KEGIATAN & $\begin{array}{l}\text { NILAI YANG } \\
\text { DILAKSANAKAN }\end{array}$ & $\begin{array}{l}\text { WAKTU } \\
\text { PELAKSANAAN }\end{array}$ & $\begin{array}{l}\text { PENANGGUNG } \\
\text { JAWAB }\end{array}$ \\
\hline 9 & $\begin{array}{l}\text { Menerima } \\
\text { Kunjungan } \\
\text { dari sekolah } \\
\text { lain }\end{array}$ & $\begin{array}{l}\text { Bersahabat } \\
\text { Komunikatif }\end{array}$ & $\begin{array}{l}\text { Kunjungan dari } \\
\text { SMA 4 Lampung } \\
\text { Timur }\end{array}$ & \\
\hline
\end{tabular}

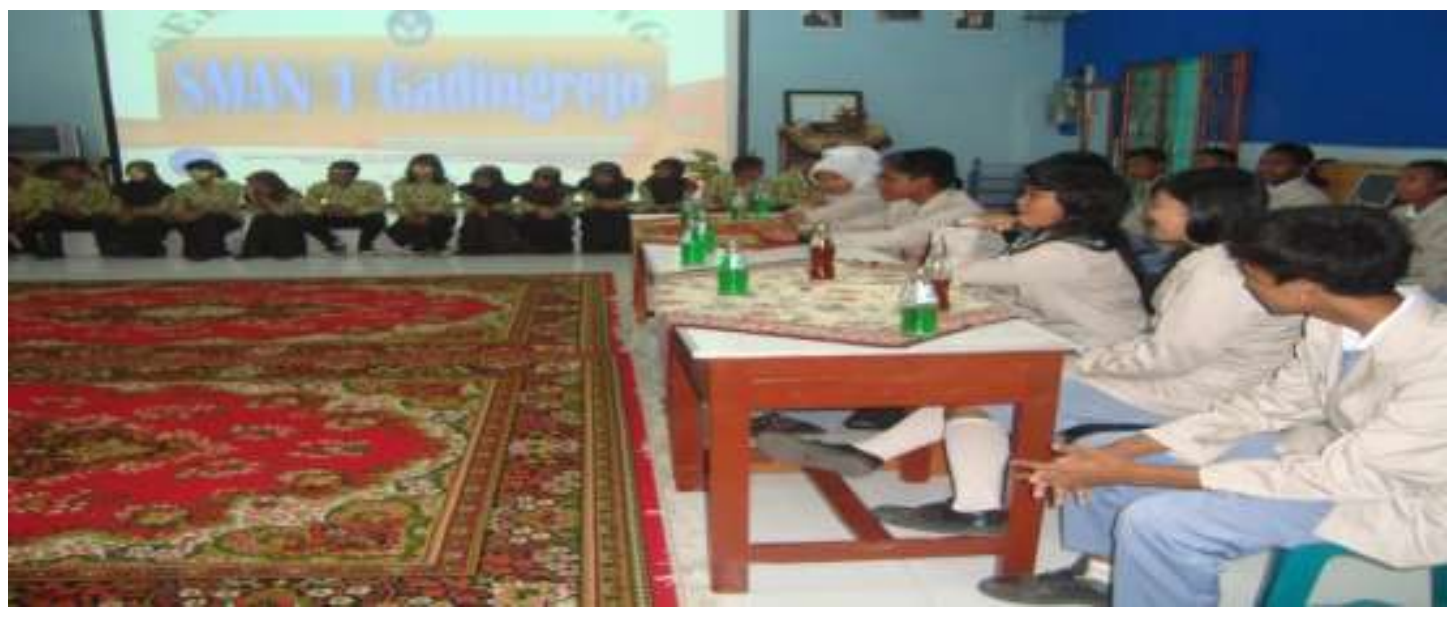

\begin{tabular}{|c|l|l|l|l|}
\hline NO & KEGIATAN & $\begin{array}{l}\text { NILAI YANG } \\
\text { DILAKSANAKAN }\end{array}$ & $\begin{array}{l}\text { WAKTU } \\
\text { PELAKSANAAN }\end{array}$ & $\begin{array}{l}\text { PENANGGUNG } \\
\text { JAWAB }\end{array}$ \\
\hline 10 & $\begin{array}{l}\text { Melibatkan } \\
\text { Masyarakat } \\
\text { dalam kegiatan } \\
\text { sekolah }\end{array}$ & Demokratis & $\begin{array}{l}\text { Buka bersama } \\
16 \text { Agustus 2011 }\end{array}$ & Guru PAI \\
\hline
\end{tabular}






\section{KESIMPULAN}

Pendidikan karakter dapat didefinisikan sebagai segala usaha yang dapat dilakukan untuk mempengaruhi karakter siswa. Pendidikan karakter mengandung tiga unsur pokok, yaitu mengetahui kebaikan (knowing the good), mencintai kebaikan (loving the good), dan melakukan kebaikan (doing the good). Pendidikan Karakter tidak sekedar mengajarkan mana yang benar dan mana yang salah kepada peserta didik, tetapi lebih dari itu pendidikan karakter menanamkan kebiasaan (habituation) tentang yang baik sehingga peserta didik paham, mampu merasakan, dan mau melakukan yang baik. Jadi, pendidikan karakter membawa misi yang sama dengan pendidikan akhlak atau pendidikan moral.

Nilai karakter yang perlu ditanamkan kepada peserta didik yang bersumber dari Agama, Pancasila, Budaya, dan Tujuan Pendidikan Nasional. Kedelapan belas nilai tersebut adalah: 1) religius, 2) jujur, 3) toleransi, 4) disiplin, 5) kerja keras, 6) kreatif, 7) mandiri, 8) demokratis, 9) rasa ingin tahu, 10) semangat kebangsaan, 11) cinta tanah air, 12) menghargai prestasi, 13) bersahabat/komunikatif, 14) cinta damai, 15) gemar membaca, 16) peduli lingkungan, 17) peduli sosial, 18) tanggungjawab
Saran dalam makalah ini adalah sebagai berikut.

a) Dalam proses pembelajaran di kelas guru sebaiknya selalu menanamkan karater siswa yang terintegrasi dalam mata pelajaran

b) Memberikan keteledananan karakter kepada siswa melalui sikap guru

c) Dalam proses pembelajaran di kelas guru menilai siswa tidak hanya pada ranah kognitif saja, tetapi juga menilai afektif dan psikomotornya.

\section{DAFTAR PUSTAKA}

Hartono.

2012.

Pengertian Pendidikan, http://fatamorghana.w ordpress.com,

Kartadinata, S. 2009. Mencari Bentuk Pendidikan Karakter Bangsa. Makalah. Fakultas Ilmu Pendidikan. Universitas Pendidikan Indonesia. Bandung. http://file.upi.edu/direktori/fip/jur._p sikologi_pend_dan_bimbingan/1950 03211974121sunarya_kartadinata/m encari_bentuk_pendidikan_karakter _bangsa.pdf. Akses: 29 Agustus 2013; 07:18 AM.

Kemendiknas. 2010., Bahan Pelatihan Pengembangan Pendidikan Budaya dan Karakter Bangsa, Jakarta: Badan Penelitian dan Pengembangan Puskur Kemendiknas

Kemendiknas. 2011. Panduan Pelaksanaan Pendidikan Karakter. Badan Penelitian dan Pengembangan Pusat Kurikulum dan Perbukuan. Jakarta 
Koesoema A. Donie, 2007. Pendidikan Karakter. Jakarta: Grasindo.

Marzuki. 2013. Revitalisasi Pendidikan Agama di Sekolah dalam Pembangunan Karakter Bangsa di Masa Depan. Jurnal Pendidikan Karakter. 3 (1): 64-76.

Mochtar Buchori (2007) , http://www.ahmadsudrajattentangpe ndidikan.org.com

Pemerintah Republik Indonesia. 2010. Kebijakan Nasional Pembangunan Karakter Bangsa Tahun 2010-2025: Jakarta.

Nency. 2013. Pendidikan Karakter Dan Kualitas Pendidikan. Padang: UNPAD

Sari, N.K. 2013. Pendidikan dan Pembinaan Karakter Bangsa. http://nuriithaa.blogspot.com/2013/0 4/pendidikan-dan-pembinaankarakter-bangsa.html. Akses: Rabu, 28 Agustus 2014; 08:51 AM.

Suyatno. 2010. Peran Pendidikan Sebagai Modal Utama Membangun Karakter Bangsa. Makalah disampaikan pada Saresehan Nasional 'Pembangunan Pendidikan Budaya dan Karakter Bangsa'. Kopertis Wilayah III: Jakarta

Widayanto. 2013. Mengimplementasikan Pendidikan Karakter Bangsa di Lingkungan Sekolah dan Masyarakat. Widyaiswara Madya BDK Surabaya. http:// bdsurabaya.kemenag.go.id/file/doku men/PBKB1.pdf. Akses: Rabu 28 Agustus 2014; 09:03 AM 